\title{
Study of the Vibratory Behavior of Composite Plates under the Effect of Different Reinforcement Parameters
}

\author{
Abdelmalek Abdelmalek ${ }^{1 *}$, Bouazza Mokhtar ${ }^{2}$ \\ 'Department of Mechanical Engineerin, University of Bechar \\ 2Department of Civil Engineering, University of Bechar, BP 147,Bechar-08000
}

\begin{abstract}
This contribution consists of the free vibratory behavior analysis of composite plates laminated; the study of the vibration in displacement of such structures rests primarily on the research of the frequencies and the clean modes, the main axis of this study is the enhancement and the discussion of the effects various geometry of plate, the reinforcement fibers orientation and the ratio orthotropic of the material on the oscillation frequencies. The choice of the model that says we have taken into consideration in the simulation, meets the objective of our study and the results are then validated by available literature results.
\end{abstract}

\section{KEYWORDS}

Shell, Plate, Composite, Laminated, Vibration, Frequency.

\section{Introduction}

In recent advances, laminated plates made of composite materials have been using intensively in many engineering application such as aerospace, marine and civil infrastructure, etc., because they possess many favorable mechanical properties such as high stiffness to weight and low density. This is particularly meaningful in aerospace and submarine structures which require high stiffness and weight-saving [1].

The published works pertaining to the vibrations of such plates are abundant $[6,7]$. The classical methods focus on thin plates and assume a straight line normal to an undeformed middle surface to remain straight and normal after middle surface deformation. But the neglect of transverse shear deformation and rotary inertia in thick plate analysis results in an overestimation of natural frequency and buckling load and underestimation of bending deflection. As the stiffness factor is greater than a certain value, the frequency parameter changes very slowly [3]. The effect of transverse shear deformation and rotary inertia was considered by Reissner [2] and Mindlin [5] in an effort to develop a more accurate thick plate model. In this first-order shear deformation theory (FSDT), it is assumed that a straight line originally normal to the middle surface remains straight.

Jiu and Chen [16] gave exact solutions for free vibration analysis of SSSS rectangular plates using Bessel functions, Misra [18] studied the free vibration analysis of isotropic plate using multiqudric radial basis function

Reddy [17] conducted a finite element code based on the theory of Yang-NorrisStavsky and confirm to asymmetric laminates, he considered composite "cross-ply" and "angle-ply" of which two sides are simply supported and the other two sides are either simply supported or free, or fixed $[19,20]$. Assuming that the displacement field 
in the thickness is a cosine function, R.K. Khare and al. [24] constructed a finite element method and were used for isotropic thick plates, rolled "crossply" asymmetrical laminates and sandwiches. A. Beakou and Touratier [21] have also developed the vibration calculation tool in their finite element code.

Although 3D analytical solutions exist only for very simple and conventional cases, they are used for the estimation of the stress and the displacement in the thickness, S. Srinivas [22] has proposed an exact solution for the free vibration of a homogeneous plate isotropic simply supported and rectangular orthotropic [23].

\section{Method of Calculus}

The composites materials are more difficult to model than an isotropic material such as iron or steel. We need to take special care in defining the properties and orientations of the various layers since each lay may have different orthotropic material proprieties. In this section, we will concentrate on the following aspects of building a composite model by choosing the proper element type.

\subsection{Shell99}

Shell99 is an 8-node, 3-D shell element with six degrees of freedom at each node. It is designed to model thin to moderately thick plate and shell structures with a side-to-thickness ratio of roughly 10 or greater. The Shell99 element allows a total of 100 uniform- thickness layers (see Fig 1). Alternately, the element allows 50 layers with thickness that may vary bilinearly over the area of the layer. If more than 100 layers are required, you can input you own material matrix. The element also allows failure criterion calculation [4]

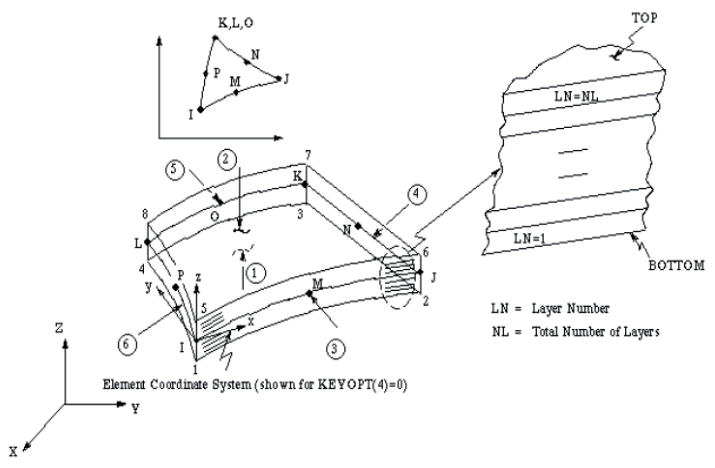

Fig. 1: Shell 99, 100-Layer Structural Shell [9].

\subsection{Numerical Examples}

Consider the model of a square orthotropic plate (length $a$, thickness $h$ with four-layer laminate $\left.\left[0^{\circ} / 90^{\circ} / 90^{\circ} / 0^{\circ}\right]\right)$ with simply supported boundary conditions.

The material parameters are: Young's modulus: $\mathrm{E} 1=40 \times 106 \mathrm{~N} / \mathrm{m}^{2}, \mathrm{E} 2=\mathrm{E} 3=1 \times 106 \mathrm{~N} / \mathrm{m}^{2}, \mathrm{G} 12=$ $\mathrm{G}_{13}=6 \times 105 \mathrm{~N} / \mathrm{m}^{2}, \mathrm{G}_{23}=5 \times 105 \mathrm{~N} / \mathrm{m}^{2}$, are the shear modulus in the 1-2, 2-3, 3-1 planes, respectively Poisson's ratio $=0.25$ and density $\rho=1 \mathrm{mg} / \mathrm{mm}^{3}$, where subscripts 1 and 2 indicate- $D$, directions parallel and perpendicular to the fibers, respectively.

The laminated plate are assumed to be of the same thickness, mass density, and made of the same linearly elastic composite material. Due to symmetry, only the below left quadrant of the plate is modeled and uniform meshes $6 \times 6$ with $\mathrm{N}=49$ nodes per side and 36 elements (see Fig. 2).

The elements of the grid are quadrilateral elements with 8 nodes. The number of elements was given in order to obtain enough precision in the results.

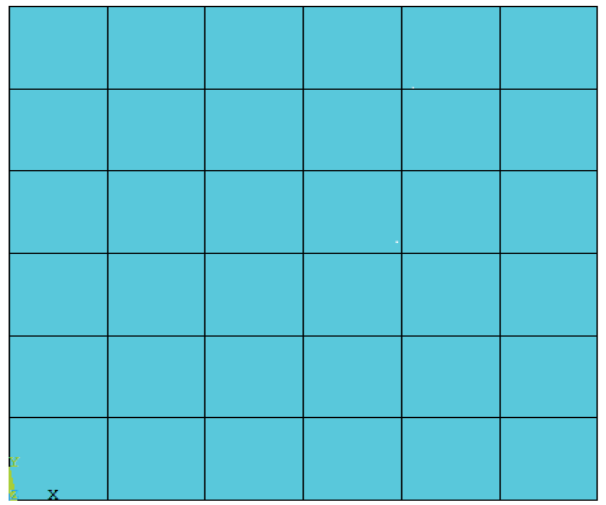

Fig. 2: Mesh of plate.

\section{Results and Discussion}

Results obtained of model Shell 99 is in table 5, for comparison, the normalized frequencies are defined as:

$\varpi=\omega a^{2} \sqrt{\rho / E_{2}} / h$

The percentage differences, between the two methods with respect to the continuous case are estimated according to the following formula:

$[\%$ Difference $=[($ value of method $1-$ value of method 2)/ value of method 2] $\times 100$ 
Table 1: Effect of thickness-to-length ratio on the non-dimensional frequency parameter $\varpi=\omega a^{2} \sqrt{\rho / E_{2}} / \mathrm{h}$ of a $\left[0^{\circ} / 90^{\circ} / 90^{\circ} / 0^{\circ}\right]$ SSSS.

\begin{tabular}{|l|l|l|l|l|l|}
\multicolumn{1}{r|}{ Methods } & $\mathbf{1 0}$ & $\mathbf{2 0}$ & $\mathbf{2 5}$ & $\mathbf{5 0}$ & $\mathbf{1 0 0}$ \\
\hline Zhen [10] & 15,165 & 17,803 & 18,240 & 18,902 & 19,157 \\
\hline Wu [11] & 15,069 & 17,636 & 18,055 & 18,670 & 18,835 \\
\hline Matsunaga [13] & 15,072 & 17,636 & 18,055 & 18,670 & 18,835 \\
\hline Cho [12] & 15,066 & 17,635 & 18,056 & 18,670 & 18,835 \\
\hline HSDT [1] & 15,070 & 17,662 & 18,087 & 18,718 & 18,882 \\
\hline FSDT [1] & 15,130 & 17,643 & 18,055 & 18,658 & 18,820 \\
\hline ANSYS & 15,130 & 17,750 & 18,036 & 18,650 & 18,810 \\
\hline
\end{tabular}

Where: SSSS = Simply supported on all four edges, $\omega$ frequency parameter.

The normalized frequency is shown in Table 1. The geometrical ratios of the laminated plate are given as follows: ratios $\mathrm{a} / \mathrm{h}=10,20,25,50$, and 100, respectively.

The results of the present method is compared

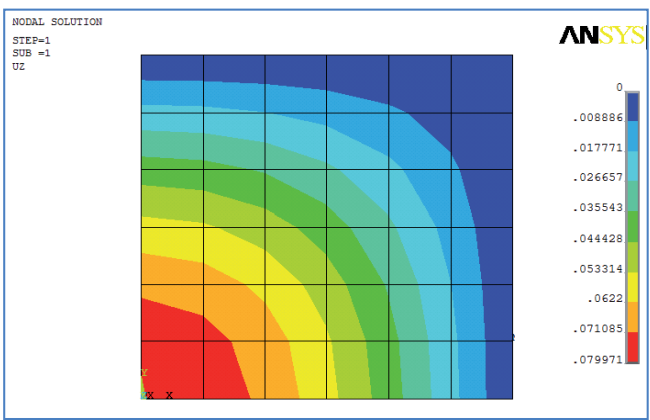

Fig. 3: (a) Mode shape 1 of a $\left[0^{\circ} / 90^{\circ} / 90^{\circ} / 0^{\circ}\right]$ SSSS laminated plate.

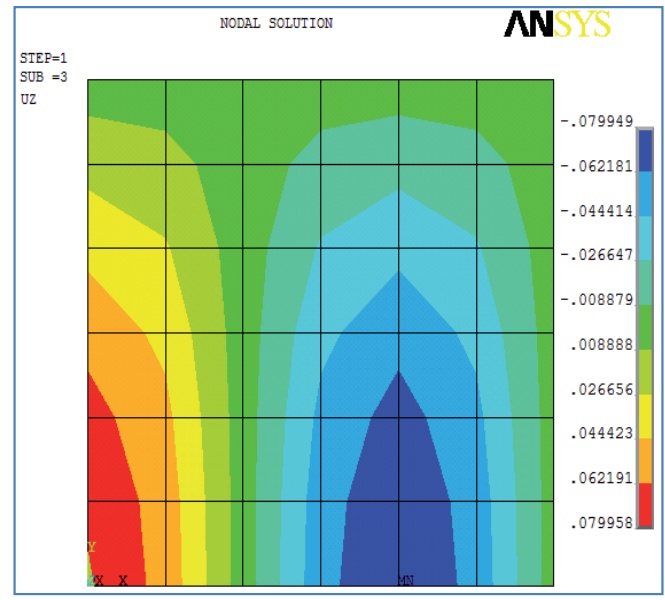

Fig. 3: (c) Mode Shape 2, with the exact solutions using FSDT, the results show that are agrees well with the available results given in Chien H. Thai and all [1], Zhen and Wanji [10], Wu and Chen [11], Matsunaga [13] and Cho et al [12].

The first four shapes modes of the left quadrant plate with $\mathrm{a} / \mathrm{h}=50$ are plotted in Fig.3.

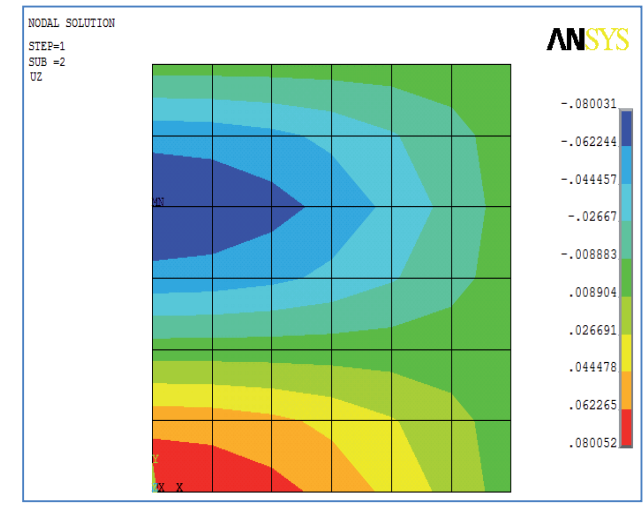

Fig. 3: (b) Mode shape 2 of a $\left[0^{\circ} / 90^{\circ} / 90^{\circ} / 0^{\circ}\right]$ SSSS laminated plate.

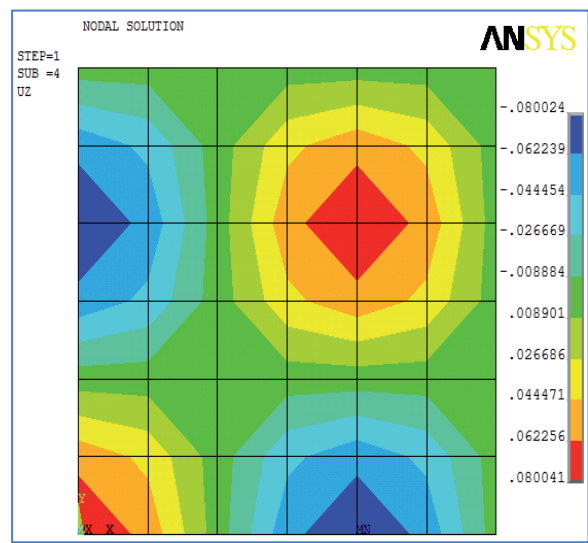

Fig. 3: (d) Mode Shape 4 
Table 2: The difference between the results of Ansys (shell 99) and FSDT [1] of plate occurs as:

\begin{tabular}{|l|l|l|l|}
\hline $\mathbf{a} / \mathbf{h}$ & FSDT [1] & \multicolumn{1}{l|}{ ANSYS } & \%Difference \\
\hline 10 & 15,130 & 15,130 & 0,00 \\
\hline 20 & 17,640 & 17,750 & $-0,62$ \\
\hline 25 & 18,055 & 18,036 & 0,11 \\
\hline 50 & 18,658 & 18,650 & 0,04 \\
\hline 100 & 18,820 & 18,810 & 0,05 \\
\hline
\end{tabular}

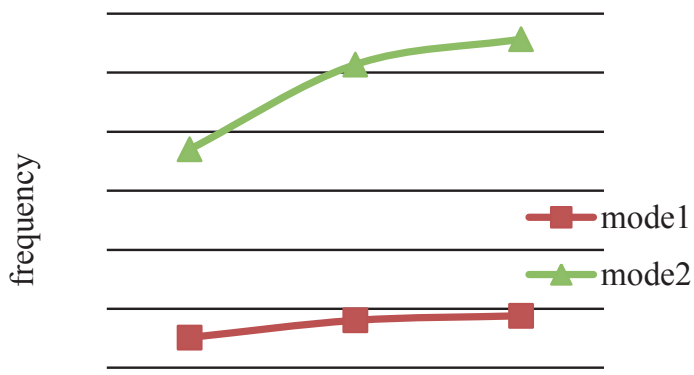

$\mathrm{a} / \mathrm{h}$

Fig. 4: Relationship between frequency and $\mathrm{a} / \mathrm{h}$ for mode 1 and 2.

In the Fig 4, we see that the ratio a / $\mathrm{h}$ increases the frequency slightly

Next we consider a six layer $\left[0^{\circ} / 90^{\circ}\right] 3$ simply supported plate, the reliability of result by ANSYS used shell 99 is also shown for the effect of various modulus ratios $E 1 / E 2=10,20,30$ and 40 . With the thickness to length ratio $\mathrm{a} / \mathrm{h}=5$

Fig.5 represents a stacking of the layers of plate laminated simulated on the computation software of structures ANSYS.

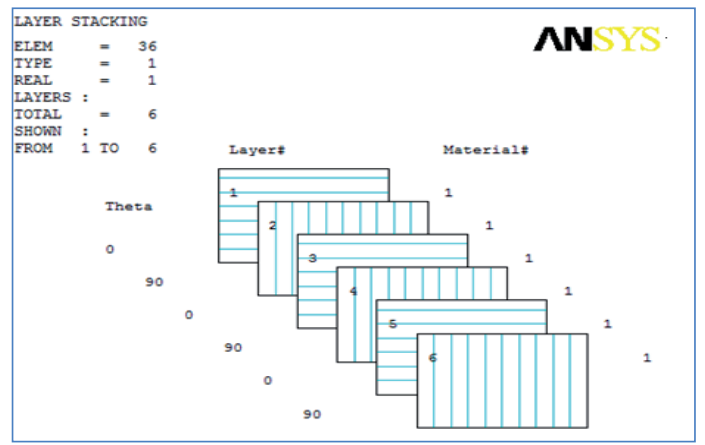

Fig. 5: stacking of the six layers of plate laminated.

The first normalized frequencies derived from the present method are listed in Table 3. The results of the present method is compared with results of
Akavci [13], Ait_yahia [15] and Aydogdu [14].

It is clear that the present results exhibit high reliability to the all solution and are very stable in case of a wide range of E1/E2 ratio.

Table 3: Effect of E1/E2 ratio on the non-dimensional frequency parameter $\varpi=\omega a^{2} \sqrt{\rho / E_{2}} / h$ of a $\left[0^{\circ} / 90^{\circ}\right] 3$ SSSS laminated plate.

\begin{tabular}{|l|l|l|l|l|}
\hline \multirow{2}{*}{ Methods } & \multicolumn{4}{c}{ E1/E2 } \\
\hline Akavci [13] & 8,40 & 9,92 & 10,86 & 11,51 \\
\hline Aydogdu [14] & 8,41 & 9,93 & 10,88 & 11,53 \\
\hline Ait_yahia [15] & 8,40 & 9,93 & 10,87 & 11,52 \\
\hline Ansys & 8,34 & 9,93 & 10,89 & 11,54 \\
\hline
\end{tabular}

\section{Conclusion}

This work offers a contribution to the study of vibration of the laminated plates of composite materials having an elastic orthotropic mechanical behavior from the numerical approach. The simulation is made using software ANSYS, applying a procedure of calculation with the respect of the steps described by this software, the vibration analysis has been performed using finite element method.

For checking of the present analysis, has numerical example has been solved and compared with other published solutions; the principal findings which we can identify from the analysis of these results are as follows:

- The results of the finite element model are in good agreement with the results available in the literature.

- The frequency parameter changes very slowly when the length- thickness ratio believes.

- The fundamental frequency of the laminated composite plates increases when the ratio of orthotropic increases.

Finally, this method of modeling for quick solutions opens new which occurred for the design of structural composites making it possible to determine the necessary frequencies.

\section{References}

[1] Chien H. Thai and all, 2012. Analysis of laminated composite plates using higher-order shear deformation plate theory and node-based smoothed discrete shear gap method. Elsevier journal of Applied Mathematical Modeling 36, 
5657-5677.

[2] Reissner. E, 1945. The effect of transverse shear deformation on the bending of elastic plates. ASME Journal of Applied Mechanics, 12: A69-A77.

[3] L.H. Wun, Y.Lu, 2011. Free vibration analysis of rectangular plates with internal columns and uniform elastic edg support, International Journal of Mechanical Sciences 53,494504.

[4] Bouazza M. and all, 2010. Bending Analysis of Symmetrically Laminated Plates. Leonardo Journal of Sciences, p. 105-116.

[5] SMindlin,R.D, 1951. Influence of rotatory inertia and shear on flexural motion of isotropic, elastic plates. ASME Journal of Applied Mechanics, 18: 31-38.

[6] Liew, K.M., Xiang,Y. and Kitipornchai, S, 1995. Research on thick plate vibration: a literature survey. Journal of Sound and Vibration, 180: 163-176.

[7] Leissa,A.W, 1973. The free vibration of rectangular plates. Journal of Sound and Vibration, 31: 257-293.

[8] H. Matsunaga, 2000. Vibration and stability of cross-ply laminated composite plates according to a global higher-order plate theory, Compos. Struct. 48, 231-244.

[9] Nakasone Y, Yoshimoto S, Stolarski T.A, 2006. Engineering Analysis with ANSYS Software. Elsevier Butterworth-Heinemann Linacre House, Jordan Hill, Oxford OX2 8DP 30 Corporate Drive, Burlington, MA 01803.

[10] W. Zhen, C. Wanji, 2006. Free vibration of laminated composite and sandwich plates using global-local higher-order theory, J. Sound Vib. 298, 333-349.

[11] C.P. Wu, W.Y. Chen, 1994. Vibration and stability of laminated plates based on a local higher-order plate theory, J. Sound Vib. 177 (4) 503-520.

[12] K.N. Cho, C.W. Bert, A.G. Striz, 1991. Free vibration of laminated rectangular plates analyzed by higher-order individuallayer theory, J. Sound Vib. 14,5 429-442.

[13] Akavci, S.S, 2009. Buckling and Free Vibration Analysis of Symmetric and Antisymmetric Laminated Composite Plates on an Elastic Foundation, Journal of Reinforced Plastics and Composites.

[14] Aydogdu, M, 2009. A new shear deformation theory for laminated composite plates. Composite Structures $89,94-$ 101.

[15] S.AIT YAHIA, 2011. Cross Shear Plate Thick Composite Materials Based On An Elastic, 1st National Seminar on Civil Engineering Materials and Environmental Protection, , Mostaganem, Algeria.

[16] Jiu, H.W and Chen, H.L, 2007. Exact solutions for free vibration analysis of rectangular plates using Bessel functions. Journal of Applied Mechanics, Vol. 74, Pp. 1247 - 1252.

[17] J.N. Reddy, 1979. Free vibration of antisymmetric, angle-ply laminated plates including tranverseshear deformation by the finite element method. Journal of Sound and Vibration, 66(4) :565-640.

[18] Misra, R.K., 2012. Free vibration analysis of isotropic plate, using multiquadric radial basis function. International Journal of Science, Environ ment and technology, Vol., No. 2, 99 $-107$.

[19] N.S. Putcha and J.N. Reddy, 1986. Stability and natural vibration analysis of laminated plates by using a mixed element based on a refined plate theory. Journal of Sound and Vibration, 104(2): 285-300.

[20] J.N. Reddy and N.D, 1985. Phan. Stability and vibration of isotropic, orthotropic and laminated plates according to a higher-order shear deformation theory. Journal of Sound and Vibration, 98(2): 157-226.

[21] A. Beakou and M. Touratier, 1993. A rectangular finite element for analysing composite multilayered shallow shells in statics, vibration and buckling. International Journal for Numerical Methods in Engineering, 36 :627-653.

[22] S. Srinivas, C.V.Joga, and A.K. Rao, 1970. An exact analysis for vibration of simply-supported homogeneous and laminated thick rectangular plates. Journal of Sound and Vibration, 12(2): 187-199.

[23] S. Srinivas and A.K. Rao, 1970. Bending, vibration and buckling of simply supported thick orthotropic rectangular plates and laminates. International Journal of Solids and Structures, 6(11): 1463-1543.

[24] R.K. Khare, T. Kant, and A.K. Garg, 2004. Free vibration of composite and sandwich laminates with a higher-order facet shell element. Composite Structures, 65(3-4):405-418

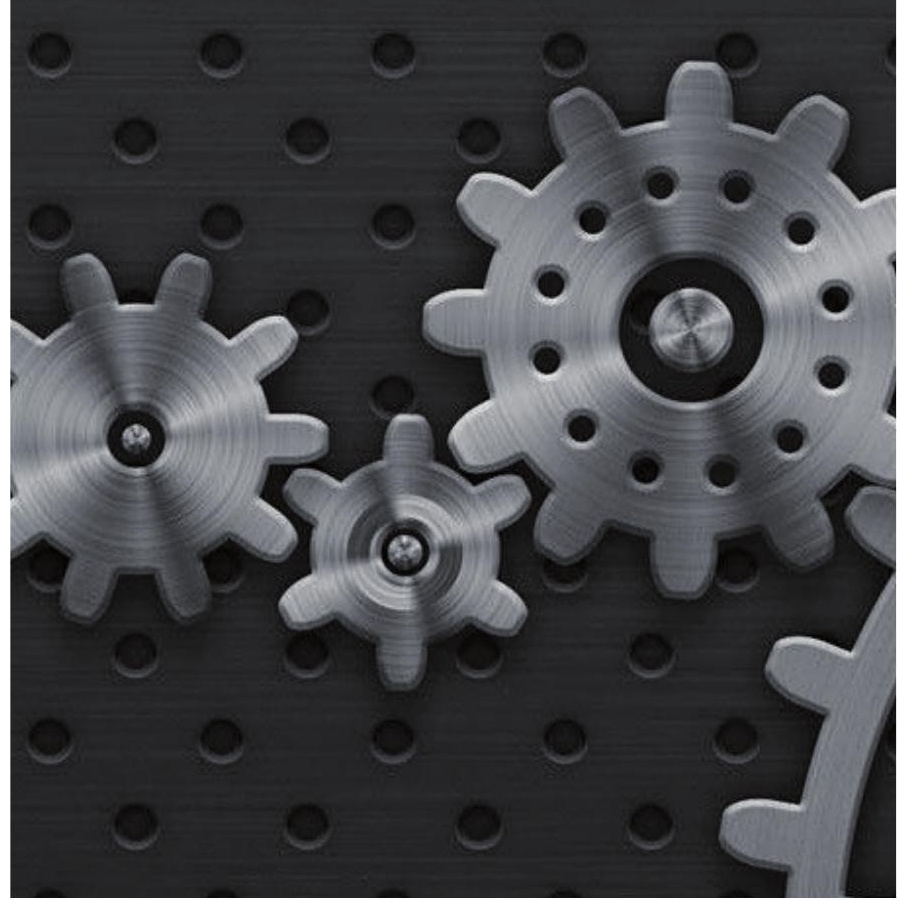


